\title{
Evaluation of Occupational Health among Brick Factory Workers
}

\author{
Jinsa Nizam ${ }^{1}$, Shashikala Manjunath ${ }^{2}$, GS Vidya $^{3}$, Chandrakala $^{4}$
}

\begin{abstract}
Introduction: Brick-kiln workers suffer from high morbidity because of their work. This demands urgent attention to the health and safety of brick-kiln workers. Very limited data on the occupational health status of brick-kiln workers are available in Karnataka. The study was primarily focused on detecting the evidence regarding the occupational hazards among brick factory workers and designing and developing better strategies for improving the working conditions of workers engaged in kilns.

Materials and methods: A total of 124 workers with at least a year of experience were included in the study. The data were collected through face-to-face interviews using a semi-structured pretested questionnaire. The information on the demography, their personal habits such as smoking, alcohol consumption, occupational exposure history, and health-seeking behavior. Specific questions/symptoms were asked on the effects of exposure to dust and other particles such as eye irritation, upper respiratory tract irritation, headache, and excessive fatigue. They were subjected to general physical examination and the basic parameters of height, weight, and blood pressure were recorded.

Results: Forty percent of workers reported health-related problems, out of which $26 \%$ of them were referred to higher centers for further check-up and treatment. Thirty-four percent were having multiple joint pains, low backache, and knee pain. Thirty-two percent complained of rhinitislike symptoms mainly due exposure to cement and other dust particles due to occupational exposure. The rest of the workers complained of bilateral leg pain, gastric irritation, chest pain on exertion, visual disturbances, and difficulty in hearing.

Conclusion: Brick kilns need a well-designed comprehensive plan and the necessary resources to prevent work-related illnesses and health risks. This strategy can improve the working conditions and also the productivity of the workers.

Keywords: Brick kiln, Occupation safety, Respiratory complications.

The Journal of Medical Sciences (2020): 10.5005/jp-journals-10045-00158
\end{abstract}

\section{INTRODUCTION}

Brick remains one of the most important building materials for construction activities in India as in any other developing countries. Data show that India is the second-largest producer of clay-fired bricks through an estimated number of $>115,000$ brick-making units. ${ }^{1}$ It is one of the largest employment-generating industries, providing jobs to about 1.5 million workers in India.

The industry follows a very primitive and informal procedure in the field of technology, recruitment of workers, wage payment systems, and daily working conditions. In India, brick making is typically a manual process. It is one of the air and landpolluting industries in the small-scale sector as per the Central Pollution Control Board (CPCB). Brick kilns have one of the most backward working environments in India that cause respiratory, gastrointestinal, psychosocial, dermatological, and musculoskeletal scatters. These hazards in the working environment are due to the high ambient temperature as well as hazards associated with manual load lifting. The vulnerable postures the workers are engaged in for long periods and the raw materials used, further increase the risk of injury. The complete absence of any personal protective device renders workers vulnerable to all sorts of injuries associated with material handling.

Brick-kiln workers suffer from high morbidity because of their work. This demands urgent attention to the health and safety of brick-kiln workers. Very limited data on the occupational health status of brick-kiln workers are available in Karnataka. The study was primarily focused on detecting the evidence regarding the occupational hazards among brick factory workers and designing
${ }^{1-4}$ Department of Community Medicine, RajaRajeswari Medical College and Hospital, Bengaluru, Karnataka, India

Corresponding Author: GS Vidya, Department of Community Medicine, RajaRajeswari Medical College and Hospital, Bengaluru, Karnataka, India, Phone: +919611011330, e-mail: drvidya.s.gowda@ gmail.com

How to cite this article: Nizam J, Manjunath S, Vidya GS, et al. Evaluation of Occupational Health among Brick Factory Workers. J Med Sci 2020;6(4):57-60.

Source of support: Nil

Conflict of interest: None

and developing better strategies for improving the working conditions of workers engaged in kilns.

\section{Materials and Methods}

After the approval from the Institutional Ethics Committee, participants were informed about the purpose, benefits of participation in the study, and verbal consent was obtained. It was a cross-sectional descriptive study. A total of 124 workers with at least a year of experience were included in the study. The data were collected through face-to-face interviews using a semistructured pretested questionnaire to obtain information on the demography and their personal habits such as smoking and alcohol consumption, occupational exposure history, and health-seeking behavior. Specific questions/symptoms were asked on the effects

() The Author(s). 2020 Open Access This article is distributed under the terms of the Creative Commons Attribution 4.0 International License (https://creativecommons. org/licenses/by-nc/4.0/), which permits unrestricted use, distribution, and non-commercial reproduction in any medium, provided you give appropriate credit to the original author(s) and the source, provide a link to the Creative Commons license, and indicate if changes were made. The Creative Commons Public Domain Dedication waiver (http://creativecommons.org/publicdomain/zero/1.0/) applies to the data made available in this article, unless otherwise stated. 
of exposure such as eye irritation, upper respiratory tract irritation, headache, and excessive fatigue, followed by a general physical medical examination, and the basic parameters of height, weight, and blood pressure were recorded.

Collected data were verified, coded as required, and entered in MS-Excel. Analysis was done by calculating frequency, percentages, and standard deviation from the data. The outcome of the study was interpreted by using tables. Data were presented in the form of tables and graphs. Descriptive statistics were presented with frequency tables. Association was illustrated with crosstables and test statistics were added in the footnotes of the tables.

\section{Results}

This cross-sectional study was conducted to examine the general health condition of 124 brick factory workers. According to the sociodemographic characteristics of the study sample, the age of the workers ranged from 21 to 58 years, with the majority of workers from 31 to 40 years. In this study, $95 \%$ of participants were literate and $5 \%$ were illiterate. Eighty-eight percent of workers were living in joint family and other workers were with third-generation members of the family. Thirty-eight percent of workers had monthly family income between Rs. 10,001 and 20,000. Similarly, 34\% had a monthly income $<$ Rs. 10,000 and $18 \%$ of workers had monthly income between Rs. 20,001 and 30,000. Only $8 \%$ had income $>$ Rs. 30,001 . Among them, 35\% of workers had an experience of $>10$ years and another $33 \%$ had an experience of 5-10 years.

Forty percent of workers reported health complaints, out of which $26 \%$ were referred to higher centers for further check-up and treatment. Thirty-four percent were having multiple joint pains common among them were low backache and knee pain. Thirtytwo percent had rhinitis-like complaints, mainly due exposure to cement and other dust particles from occupational exposure. Others had bilateral leg pain, gastric irritation, chest pain on exertion, visual disturbances, and difficulty in hearing (Table 1).

\section{Discussion}

As observed in a study conducted by Dinesh Rupakheti, Pranil Man Singh Pradhan, Prem Basel on occupational safety and health vulnerability among brick factory workers in Dhading district of Nepal, four-fifths of the participants experienced occupational safety and health vulnerability. ${ }^{2}$

Association between sociodemographic factors with health hazards is shown in tables. In our study, the majority of health complaints were orthopedics-related issues. It is more frequent among the 31 to 40 years of age group with multiple joint pain having major complaints. Then, it is followed by respiratory complaints having a dry cough, breathing difficulty rhinitis as major issues. These findings are similar to a study by Joshi et al., ${ }^{2,3}$

Table 2 shows the relation between years of work experience and health problems in brick-kiln workers. Our study revealed that increasing years of experience contributed to an increased number of workers having health problems which were mainly orthopedics-related issues. Lifting heavy weights, maintaining improper posture, and repetitive movements are hazards that lead to chronic orthopedics-related issues. This is in agreement with a study by Imelda et al. ${ }^{4}$ However, this is in contrast with the study by Rupakheti et al. ${ }^{2}$

We analyzed (Table 3) family income and mode of treatment they have chosen. The majority of factory workers were from low-

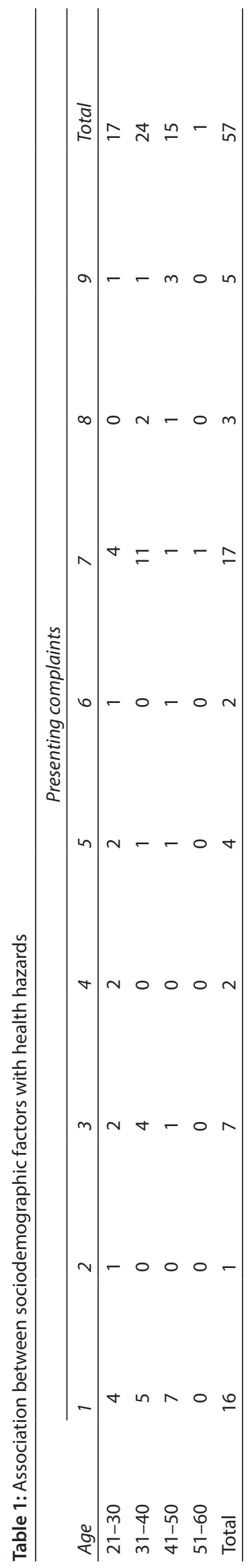




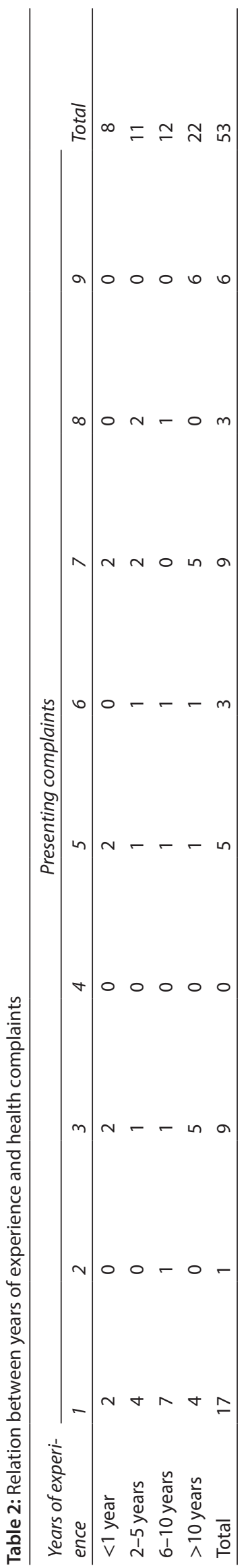

Table 3: Relation between family income and the mode of treatment they are choosing

\begin{tabular}{llll}
\hline & \multicolumn{3}{c}{ Mode of treatment } \\
\cline { 2 - 4 } Income & $\begin{array}{l}\text { No treatment } \\
\text { taken }\end{array}$ & Self-medication & Doctor's advice \\
\hline$<10 \mathrm{~K}$ & 0 & 40 & 2 \\
$10 \mathrm{~K}-20 \mathrm{~K}$ & 2 & 42 & 4 \\
$20 \mathrm{~K}-30 \mathrm{~K}$ & 0 & 22 & 1 \\
$>30 \mathrm{~K}$ & 0 & 10 & 1 \\
Total & 2 & 114 & 8 \\
\hline
\end{tabular}

income groups and they resorted to self-medication irrespective of the source of income. ${ }^{3}$

We also found (Table 4) in our study, irrespective of their educational level, the majority of factory workers choose selfmedication for health complaints. Workers having higher secondary education and better educational status showed dependence on smoking and alcohol. Smoking may be a contributory factor for respiratory disorders they suffer from.

\section{Conclusion}

The brick-kiln factory workers are more susceptible to occupational safety and health vulnerability. This demands urgent attention to the health and safety program, which must include regular in-service training of workers, emphasizing the health risks in brick-kiln work, preventive measures, technological interventions, etc. Health surveillance of workers will be beneficial for achieving a better health status. Labor seems to be the most critical capital in every industry. Based on the results of this study, occupational health hazards in these industrial units affect the general health of workers. If in the future, prevention programs in the work environment are not implemented, a high percentage of them would suffer from health-related problems.

\section{Recommendations}

Brick kilns need a well-designed, comprehensive plan and the necessary resources, to prevent work-related illnesses, health risks and improve the working conditions and productivity of the workers. Some of the improvements may be in the following directions:

- Employees' training and education programs for identifying hazardous situations, safety measures, health issues, emergency, and first-aid methods.

- Provide drinking, bathing, toilet, and washing facilities for workers.

- Supply adequate and appropriate protective equipment for all workers.

- Encourage workers to go for treatment of unattended symptoms/illnesses to recognized medical centers.

- Provide workers basic, hands-on training in first-aid, and cardiopulmonary resuscitation procedures.

- Immunize workers and their children against tetanus, hepatitis (A and B) typhoid, COVID-19 vaccine.

- Ensure yearly medical surveillance for employees.

- To provide health education related to occupational hazards and their prevention in brick factory workers. 
Table 4: Irrespective of their educational level

\begin{tabular}{|c|c|c|c|c|c|c|}
\hline \multirow[b]{2}{*}{ Education } & \multicolumn{3}{|c|}{ Mode of treatment } & \multicolumn{3}{|c|}{ Personal habits } \\
\hline & $\begin{array}{l}\text { No treatment } \\
\text { taken }\end{array}$ & Self-medication & Doctor's advice & H/O dust allergy & Smoking & Alcohol drinking \\
\hline Illiterate & 0 & 7 & 0 & 0 & 0 & 1 \\
\hline Primary & 0 & 1 & 1 & 0 & 1 & 2 \\
\hline Middle & 0 & 13 & 1 & 2 & 2 & 3 \\
\hline High school & 1 & 46 & 4 & 6 & 9 & 11 \\
\hline Diploma & 1 & 47 & 2 & 2 & 12 & 14 \\
\hline Total & 2 & 114 & 8 & 10 & 24 & 31 \\
\hline
\end{tabular}

\section{References}

1. Ebrahimia K, Tajikb R, Karamic T, et al., Evaluation of occupational noise exposure and general health of workers in industrial sites: $A$ case study, Social Determinants of Health Research Center, Research Institute for Health Development, Kurdistan University of Medical Sciences, Sanandaj, Iran Department of Occupational Health Engineering, School of Public Health, Arak University of Medical Sciences, Arak, Iran Department of Chemistry, University of Kurdistan, Sanandaj, Iran.
2. Rupakheti D, Pradhan PMS, Basel P. Occupational safety and health vulnerability among brick factory workers in Dhading District, Nepal. Ann Global Health 2018;84(3):481-487. DOI: 10.29024/aogh. 2313.

3. Joshi S, Shrestha S, Vaidya S. Occupational safety and health studies in Nepal. Int J Occupat Safety Health 2011;1(1):19-26. DOI: 10.3126/ ijosh.v1i1.4725.

4. Imelda O, Curiel R, Contreras R, et al. Occupational health and ergonomic risks in brick manufacturers. COJ Rev Res 2019;2(2):000532. 